\title{
Health information systems to improve health care: A telemedicine case study
}

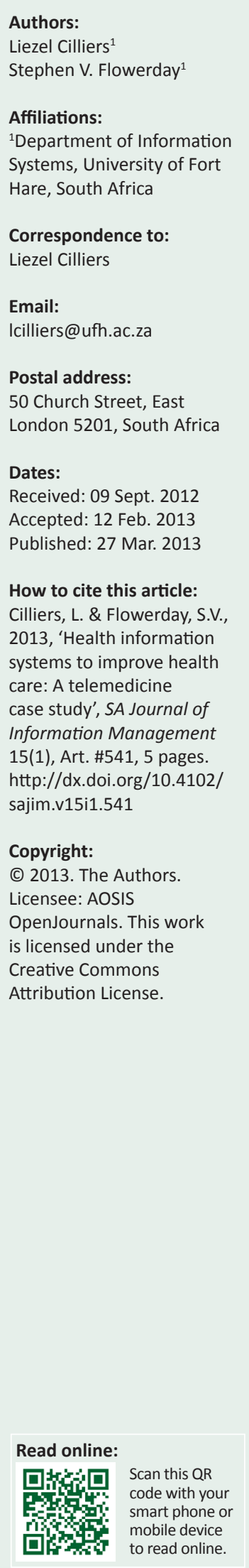

Background: E-health has been identified as an integral part of the future of South African public healthcare. Telemedicine was first introduced in South Africa in 1997 and since then the cost of running the Telemedicine projects has increased substantially. Despite these efforts to introduce the system, only $34 \%$ of the Telemedicine sites in South Africa are functional at present.

Objectives: Literature has suggested that one of the barriers to the successful implementation of health information systems is the user acceptance by health care workers of systems such as Telemedicine. This study investigated the user acceptance of Telemedicine in the public health care system in the Eastern Cape Province, making use of the Unified Theory of the Use and Acceptance of Technology.

Method: The study employed a quantitative survey approach. A questionnaire was developed making use of existing literature and was distributed to various clinics around the province where Telemedicine has been implemented. Statistics were produced making use of Statistical Package for the Social Sciences (SPSS).

Results: In general, the health care workers did understand the value and benefit of health information systems to improve the effectiveness and efficiency of the health care system. The barriers to the effective implementation of a health information system include the lack of knowledge and the lack of awareness regarding the Telemedicine system. This in turn means that the user is apprehensive when making use of the system thus contributing to less frequent usage.

Conclusion: Health care workers do acknowledge that information systems can help to increase the effectiveness of the health care system. In general, the acceptance of Telemedicine in the Eastern Cape Department of Health is positive, but in order to integrate it into standard work practices, more must be done with regards to the promotion and education of telemedicine.

\section{Introduction}

\section{Background}

Quality healthcare is considered a fundamental human right for all citizens in South Africa. The challenge remains in providing quality health care to all, especially to people living in rural areas (Colvin et al. 2011). The average doctor to patient ratio in South Africa is calculated at 1:1 300 with some rural areas recording a 1:100 000 ratio (IRIN 2008; Jacobs 2007).

Health information systems have been identified as a possible solution that can be used to alleviate the disparity between rural and urban health care services (Fichman, Kohli \& Krishnan 2011; Kolodner, Cohn \& Friedman 2008). Information systems can provide the tools to capture, store, processes and communicate information to the relevant decision makers to coordinate health care at the individual and population levels. This improves the quality of care and reduces health care costs (Fichman et al. 2011). An example of such a Health Information system, which makes use of both electronic communication and information technology to provide services to the health care sector, is e-health (WHO 2013). The technology is used to expand, assist and enhance health care activities and is not a substitute for health care workers (Oh et al. 2005). There are several key application areas within e-health as illustrated in Figure 1. These include health informatics, Telehealth and Telemedicine (WHO 2013).

Telemedicine, meaning medicine at a distance, provides very distinct advantages for health care workers making use of the system (WHO 2013). There are two primary delivery methods that can be used: namely real-time, and a store and forward approach. The most popular method due to connectivity problems is the second approach where a message is sent to the specialist to review later or at their convenience. For this approach, all that is needed is a basic computer with Internet connectivity and camera (Singh 2006). The goal of Telemedicine is to increase the 
accessibility of specialised health care in rural areas. Patients in rural areas do not have to travel long distances to urban hospitals in order to access specialist care, whilst waiting times and transportation costs are reduced. Health care workers also benefit from the system as urban colleagues are able to support and teach those in rural areas making use of the system (WHO 2013; Wootton et al. 2009).

\section{E-health trends in South Africa Focus of the study}

Telemedicine has become an integral part of the Department of Health's E-health plan in South Africa, with more than R15 million being invested in various Telemedicine projects in recent years (Motsoaledi 2010). Despite these investments, it has been reported that the uptake of the technology has been limited with only $34 \%$ of Telemedicine sites operational (Van Dyk, Fortuin \& Schutte 2012; Motsoaledi 2010; Jack \& Mars 2008). The poor uptake of Telemedicine is not unique to South Africa with many authors reporting similar results in other developing countries (Mars 2012; Ovretveit et al. 2007; Medecins Sans Frontiers 2007). Previous literature reported that the technology was not reliable due to frequent interruptions of electricity supply, poor connectivity and low bandwidth (Mars 2012; Fortuin \& Molefi 2007; Jack \& Mars 2008). Whilst these problems have been addressed since the inception of Telemedicine, the usage of the technology has remained low (Jack \& Mars 2008). This has necessitated a new research focus area with particular emphasis on the human and organisational factors involved (Mars 2012; Van GemertPijnen et al. 2012). One of the factors that has been identified as a possible obstacle for the successful implementation of Telemedicine is user acceptance (Nwabueze et al. 2009; Pagliari et al. 2005).

Telemedicine has been introduced at six district hospitals and 25 clinic sites around the Eastern Cape in the past five years. These pilot sites have not produced the desired results, and it was found that the technology was underutilised or not used at all. Therefore, an investigation is needed before any financial investment is made in further sites (Telemedicine Operation Plan E-health 2009). The objective of this article is then to investigate if user acceptance is a factor for the poor

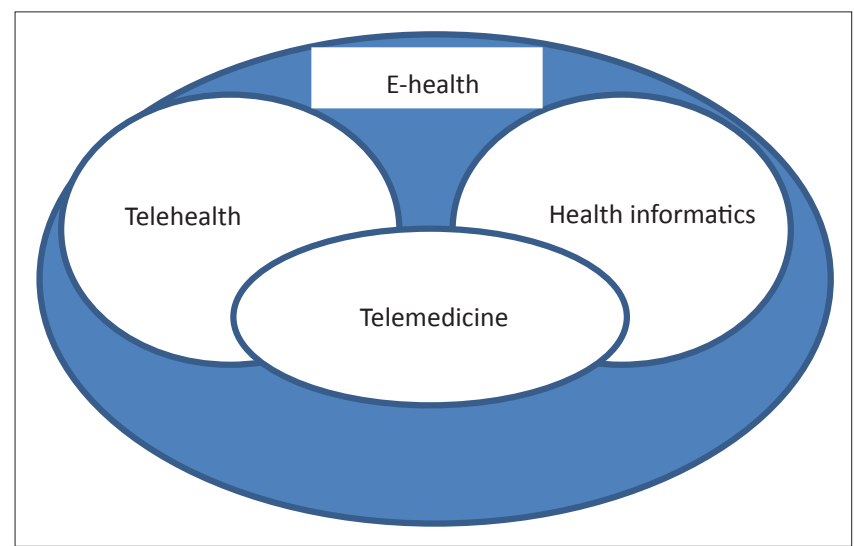

FIGURE 1: Various services as part of the E-health system. uptake of Telemedicine in the Eastern Cape Department of Health whilst making use of the Unified Theory of Acceptance and Use of Technology (UTAUT) to prove or disprove this concept.

\section{Contribution to the field}

The Unified Theory of Acceptance and Use of Technology (UTAUT) was used as a theoretical framework for this study. The UTAUT was developed by Venkatesh in order to explain behavioural intention to use a technology. The model consists of four key constructs: performance expectancy, effort expectancy, social influence, and facilitating conditions (Venkatesh, Thong \& Xu et al. 2012). The theory was found to explain $70 \%$ of the variance in behavioural intention to use a technology and about $50 \%$ of the variance in technology use (Venkatesh et al. 2012). Since the inception of UTAUT, it has become a baseline model in this area of technology adoption and has been tested in a variety of settings including health information systems (Chang 2007). Additionally, it has been applied to a variety of technologies in both organisational and non-organisational settings contributing to its generalisability (Neufeld et al. 2007).

\section{Research design}

This research made use of a positivistic, quantitative research methodology. A questionnaire was developed and piloted. From the pilot study, it was established that the questionnaire is user friendly. The study population of this research project was defined as any health care worker for the multidisciplinary team employed at any of the Eastern Cape Department of Health telemedicine sites within the province. Statistical Package for the Social Sciences (SPSS) was used to perform the statistical analysis. Validation of the final results was conducted by four experts in Telemedicine and technology acceptance in general (Cilliers \& Flowerday 2011). Feedback from these experts was then incorporated into the final recommendations and conclusions of the study. Exclusion criteria for this study included Telemedicine in the private sector, technology issues directly associated with telemedicine, as well as budgetary and other financial constraints faced by the implementers of the technology (Cilliers \& Flowerday 2011).

\section{Ethical consideration}

Ethical approval was obtained from both the University of Fort Hare Ethics Committee and Department of Health Ethics Committee before the study was conducted. Study participants also received a covering letter explaining the purpose of the study and informing them that participation in the study was voluntary.

\section{Study population}

Seventy-five questionnaires were distributed to health care workers at 31 Telemedicine sites in the Eastern Cape Health Department. Health care workers from the multidisciplinary team including nurses, doctors, dentists and radiologists, 
were randomly selected to participate. The return rate for the questionnaire was $76 \%$. The majority of the study population $(86 \%)$ consisted of women. More than a third of the participants were younger than 30 years of age $(36.8 \%)$, whilst $45.6 \%$ were between the ages of $31-49$ years of age. The health care workers older than 50 years of age represented $17.6 \%$ of the study population. The study participants indicated that $43 \%$ worked in an urban setting and $56 \%$ in a rural area. This is consistent with the reported statistics for the larger population in the Eastern Cape. The educational level of the participants included $62 \%$ who obtained a formal qualification, 22\% completed Grade 12 and 14\% who completed Grade 10. The study population consisted of a multi-disciplinary team including medical doctors, dentists, pharmacists and allied health professionals including radiographers. The majority of the study population consisted of nurses (30\%) and student nurses (22.8\%). The following section provides insight into the four major constructs of the UTAUT model.

\section{Results and discussion Performance expectancy}

The main objective of a health information system, such as telemedicine, is to improve health care services whilst reducing costs (Keeton 2012). Performance expectancy represents the degree to which an individual believes that using the system will assist them in attaining their goals in job performance (Venkatesh et al. 2003).

For the question, 'I find Telemedicine useful in my job', a significant statistical difference was found when measured against educational level as well as where the facility was located. From the health care workers with a degree qualification, $72 \%$ indicated that telemedicine would be useful in their job, whilst $100 \%$ of the health care workers with a Grade 12 or diploma qualification answered positively $(\alpha=19.647 ; p<0.05)$.

Health care workers working in rural areas (clinics, community health centres and district hospitals) found Telemedicine to be more useful than those working in the secondary hospitals in urban areas $(\alpha=29.629 ; p<0.05)$. Figure 2 illustrates how useful the health care workers in various settings found telemedicine. The reason for the higher percentages for the rural areas is that these areas stand the most to benefit from telemedicine.

\section{Effort expectancy}

Effort expectancy is defined as the degree of ease associated with the use of the system (Venkatesh et al. 2003). The majority of health care workers found the system to be user-friendly. This is illustrated by the results of the questions, 'I find the telemedicine system easy to use' and 'I found it easy to learn how to use the system'. Accordingly, $71 \%$ of the respondents found the system easy to use and $69 \%$ agreed that it was easy to learn how to use the system.

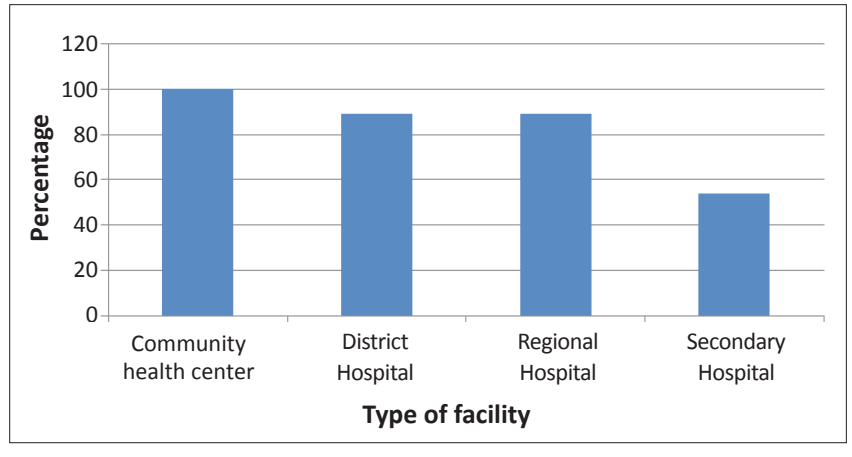

FIGURE 2: Perception of the usefulness of Telemedicine according to place of work of health care workers.

Effort expectancy was found to be statistically significant for the area in which the facility is located, as well as the general knowledge of telemedicine of the health care workers.

More health care workers in the rural areas (81.4\%) agreed that the Telemedicine unit was easy to use, followed by the health care workers in urban areas (69.7\%). Health care workers in both the urban (72\%) and rural $(81.5 \%)$ areas indicated that they felt it was easy for them to learn how to make use of the Telemedicine system $(\alpha=21.279 ; p<0.05)$. This can be attributed to the increased effort that was made by the Department of Health to educate health care workers in the rural areas to not only use Telemedicine, but also the increased effort to ensure that the health care workers become computer literate. This is supported by Lungo (2008) who proposes that when education is provided to familiarise the user with a specific computer programme, it will be influenced by the computer literacy level of the user.

The majority of the participants $(85.85 \%)$ who considered themselves knowledgeable regarding Telemedicine indicated that they could use the technology whilst those who did not consider themselves knowledgeable regarding the technology (52.7\%) predictably felt that their interactions with the Telemedicine system were not clear and understandable. Participants who indicated they were not knowledgeable regarding telemedicine agreed that it was easy for them to learn how to make use of telemedicine $(52.7 \%)$, as did those who perceived themselves knowledgeable regarding the technology $(87.85 \%)$.

\section{Social influence}

Venkatesh et al. (2003) defined social influence as the extent to which an individual allows the opinions of others to influence their decision to use the system. In this category, a positive correlation was found for the perceived knowledge of Telemedicine. Health care workers who considered themselves knowledgeable about Telemedicine agreed with the statement that other people would influence their behaviour to use the technology (79.15\%), whilst only 50\% of those who did not consider themselves knowledgeable agreed with the statement $(\alpha=19.047 ; p<0.05)$.

\section{Facilitating conditions}

Holden and Karsh (2010) stated that facilitating conditions when dealing with technology acceptance in health care is 


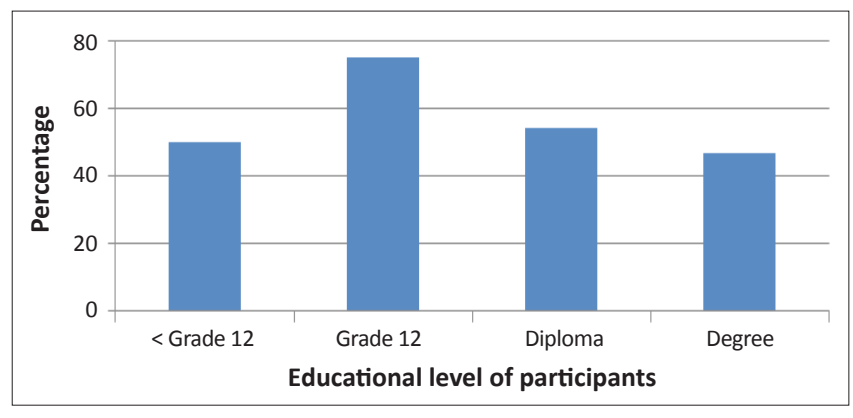

FIGURE 3: Perception of resources necessary to use telemedicine according to qualifications of health care workers.

a very important factor. Facilitating conditions include resource availability such as technical assistance, knowledge of the system and compatibility with other systems already in use (Venkatesh et al. 2003).

Half of the participants (54.4\%) indicated that they thought they did have the resources necessary to make use of Telemedicine. Two thirds $(64.9 \%)$ indicated that they did have access to technical assistance if necessary, whilst $40.3 \%$ indicated that the technology is not compatible with the systems already in use at their health care facility.

The resources necessary to make use of telemedicine tested statistically significant for qualification and knowledge of telemedicine. Qualification provided the following positive correlation with the statement: 'I have the resources, such as technical assistance, necessary to use telemedicine' $(\alpha=18.107 ; p<0.05)$. The following graph (Figure 3 ) illustrates the result in percentage for this question.

Interestingly, the health care workers who considered themselves knowledgeable regarding the technology were far less confident about technical assistance (57\%) than the group that perceived themselves as not knowledgeable $(81.6 \%)(\alpha=19.566 ; p<0.05)$.

In general, the majority of health care workers in this study believed that Telemedicine would improve their productivity in the workplace $(67 \%)$ or, at the very least, be useful during their daily activities (80\%). The advantage of Telemedicine cited by health care workers in urban areas included less time being spent on outreach activities and fewer patients being referred incorrectly to urban centres. For rural based health care workers, the advantages of incorporating telemedicine in their daily activities included shorter waiting times for diagnoses and treatment as well as support from colleagues in urban centres.

\section{Conclusion}

The health care workers in the Eastern Cape Department of Health found Telemedicine to increase their productivity, quality and efficiency of work. The behavioural intent of the health care workers was also found to be favourable for the future use of the system. Most of the health care workers found the system easy to use but interestingly, those in the urban areas reported more difficulty with this aspect. As the awareness regarding Telemedicine decreased, so did the ease of use and frequency with which the system was used. Apprehension and fearfulness also increased as the knowledge of Telemedicine decreased. Social influence and facilitating conditions were also found to influence the acceptance of health care workers of telemedicine.

Awareness regarding the benefits of telemedicine must be improved in order to facilitate the acceptance of the technology. Aligned with this, is the education of health care workers regarding telemedicine in order to increase knowledge which will decrease apprehension and fearfulness, whilst at the same time increase ease of use.

\section{Acknowledgements Competing interest}

The authors declare that they have no financial or personal relationship(s) that may have inappropriately influenced them in writing this paper.

\section{Authors' contributions}

L.C. (University of Fort Hare) completed the dissertation in fulfillment of the requirements for the degree Masters of Commerce in Information Systems in the Faculty of Management and Commerce of the University of Fort Hare. S.V.F. (University of Fort Hare) was the supervisor to this student.

\section{References}

Chang, I.C., Hwang, H.G., Hung, W.F. \& Li, Y.C., 2007, 'Physicians' acceptance of pharmacokinetics-based clinical decision support systems', Expert Systems with Applications 33(2), 296-303. http://dx.doi.org/10.1016/j.eswa.2006.05.001

Cilliers, L. \& Flowrday, S.V., 2011, 'Will computer literacy affect telemedicine acceptance among health care workers', viewed 5 January 2013, from http:// www.resnes.co.za/colloquium/2011-proceedings/papers/resnes2011_p11.pdf

Colvin, R., Mia Shim, M., Brock, D. \& Todd, G., 2011, 'Dermatological diagnostic acumen improves with use of a simple telemedicine system for underserved areas of South Africa', Telemedicine and e-Health 17(5), 363-367.

Fichman, G., Kohli, R. \& Krishnan, R., 2011, 'The role of information systems in healthcare: Current research and future trends', Information Systems Research 22, 419-327. http://dx.doi.org/10.1287/isre.1110.0382

Fortuin, J. \& Molefi, M., 2007, 'Implementing Telemedicine in South Africa - A South African Experience', International Hospital Federation Reference Book 2006/2007, Dubai.

Holden, R.J. \& Karsh, B.T., 2010, 'The Technology Acceptance Model: Its past and its future in health care', Journal of Biomed Informatics 43(1) 159-172.http://dx.doi. org/10.1016/j.jbi.2009.07.002

IRIN, 2008, 'South Africa wanted - 4,000 doctors', viewed 5 January 2013, from http:// www. plusnews.org/Report/79241/SOUTH-AFRICA-WANTED-4-000-doctors

Jack, C. \& Mars, M., 2008, 'Telemedicine a need for ethical and legal guidelines in South Africa', South African Family Practice 50, 60-61.

Jacobs, F., 2007, ' 185 - The Patients per Doctor map of the world', viewed 5 January 2013, from http://bigthink.com/strange-maps/185-the-patients-per-doctor-mapof-the-world

Keeton, C., 2012, 'Measuring the impact of e-health', Bull World Health Organisation 90, 326-327. http://dx.doi.org/10.2471/BLT.12.020512

Kolodner, R.M., Cohn, S.P. \& Friedman, P., 2008, 'Health information technology: Strategic initiatives, real progress', Health Affairs 27, 391-395. http://dx.doi. org/10.1377/hlthaff.27.5.w391

Lungo, J.H., 2008, 'The reliability and usability of district health information software: Case studies from Tanzania', Tanzania Journal of Health Research 10, 139. http:// dx.doi.org/10.4314/thrb.v10i1.14340

Mars, M., 2012, 'Telepsychiatry in Africa - A way forward?', African Journal of Psychiatry 15, 215-217.

Medecins Sans Frontiers, 2007, 'Help wanted: Confronting the health care crises to expand HIV/AIDS treatment', viewed 6 January 2013, from http://www. doctorswithoutborders.org/publications/article.cfm?id=2881

Motsoaledi, M., 2010, 'Speaking notes for Dr. A.P Motsoaledi for the 1st Southern African Telemedicine Conference', viewed 22 February 2013, from http://www. doh.gov.za/show. php?id=2104 
Neufeld, J., Dong, L. \& Higgins, C., 2007, 'Charismatic leadership and user acceptance of information technology', European Journal of Information Systems 16, 494-510. http://dx.doi.org/10.1057/palgrave.ejis.3000682

Nwabueze, S.N., Meso, N.P., Kifle, M., Okoli, C. \& Chustz, M., 2009, 'The effects of culture of adoption of Telemedicine in medically underserved communities', Proceedings of the 42nd Hawaii International Conference on System Sciences, Hawaii, United States of America, 2009, pp. 1-10.

Oh, H., Rizo, C., Enkin, M., Jadad, A., 2005, 'What is eHealth: A systematic review of published definitions', Journal of Medical Internet Research 24, 7 .

Ovretveit, J., Scott, T., Rundall, T.G., Shortell, S.M. \& Brommels, M., 2007, 'Improving quality through effective implementation of information technology in healthcare' International Journal for Quality in Health Care 19(5), 259-266. http://dx.doi. org/10.1093/intqhc/mzm031

Pagliari, C., Sloan, D., Gregor, P., Sullivan, F., Detmer, D., Kahan, P. et al., 2005, 'What is eHealth: A scoping exercise to map the field', Journal of Medical Internet Research 7(1), 201-210. http://dx.doi.org/10.2196/jmir.7.1.e9 PMid:15829481

Singh, V., 2006, 'Telemedicine and Mobile Telemedicine Systems', viewed 8 January 2013, from http://works.bepress.com/vikas_singh
Telemedicine Operational Plan E-health, 2009, 'Operational Plan for Eastern Cape', viewed 7 February 2013, from http://www.ecdoh.gov.za/uploads/ files/260308124225.pdf

Van Dyk, L., Fortuin, J. \& Schutte, C., 2012, 'A Maturity model for Telemedicine Implementation', eTELEMED 2012: The Fourth International Conference on eHealth, Telemedicine, and Social Medicine, Cape Town, South Africa, pp. 69-71.

Van Gemert-Pijnen, J.E.W.C., Wynchank, S., Covvey, H.D. \& Ossebaard, H.C., 2012, 'Improving the credibility of electronic health technologies', Bull World Health Organ 90, 323-323A. http://dx.doi.org/10.2471/BLT.11.099804

Venkatesh, V., Morris, M.G., Davis, G.B. \& Davis, F.D., 2003, 'User acceptance of information technology: Toward a unified view', MIS Quarterly 27, 425-478.

Venkatesh, V., Thong, J.Y.L. \& Xu, X., 2012, 'Consumer acceptance and use of information technology: Extending the unified theory of acceptance and use of technology', MIS Quarterly 36(1), 157-178.

WHO, 2013, 'E-Health', viewed on 6 January 2013, from http://www.who.int/trade/ glossary/story021/en/index.htm

Wootton, R., Patil, E., Scott, R.E. \& Ho, K., 2009, 'Telemedicine in the Developing World', Royal Society of Medicine Press, London. 